\title{
Persistent sensitization of dopamine neurotransmission in ventral striatum (nucleus accumbens) produced by prior experience with $(+)$-amphetamine: a microdialysis study in freely moving rats
}

\author{
Terry E. Robinson, Phillip A. Jurson, Julie A. Bennett and Kris M. Bentgen \\ Department of Psychology and Neuroscience Program, The University of Michigan, Ann Arbor, MI 48109 (U.S.A.)
}

(Accepted 3 May 1988)

Key words: Sensitization; Amphetamine; Dopamine; Nucleus accumbens; Dialysis; Dopamine release; Locomotion; Stereotyped behavior; Stimulant; Chronic drug effect; Amphetamine psychosis; Neural plasticity

\begin{abstract}
In humans the repeated use of amphetamine (AMPH) produces a hypersensitivity to the psychotogenic effects of AMPH that persists for months to years after the cessation of drug use. To explore the neurobiological basis of this phenomenon the long-term effects of dextroamphetamine $((+)$-AMPH) on brain monoamines and behavior were studied in an animal model of AMPH psychosis. An escalating dose pretreatment regimen (from 1 to $10 \mathrm{mg} / \mathrm{kg}$ over 5 weeks) was used to mimic the pattern of drug use associated with the development of addiction and AMPH psychosis. The effect of pretreatment with AMPH on dopamine (DA) release in the ventral striatum (nucleus accumbens) was determined by measuring the extracellular concentrations of DA and DA metabolites using in vivo microdialysis, both before and after an AMPH challenge. The postmortem tissue concentrations of DA, serotonin and their metabolites were measured to determine if this treatment was neurotoxic. Escalating doses of $(+)$-AMPH were not neurotoxic, and 25-30 days after the cessation of drug treatment animals showed relatively normal levels of spontaneous motor activity across the day-night cycle. However, AMPH pretreatment produced robust behavioral sensitization. Animals showed a marked hypersensitivity to the motor stimulant effects of an AMPH challenge, even after 15-20 days of withdrawal. Most importantly, this hyperdopaminergic behavioral syndrome was accompanied by significantly elevated DA release in the ventral striatum. In contrast, AMPH pretreatment had no effect on the basal extracellular concentrations of DA. It is suggested that the sensitization produced by chronic AMPH use is due to enduring changes in the releasability of DA, and that this may represent an example of neural plasticity common to other forms of behavioral adaptation.
\end{abstract}

\section{INTRODUCTION}

People who abuse psychomotor stimulant drugs, such as amphetamine (AMPH) or cocaine, frequently develop a drug-induced paranoid psychotic condition characterized by delusions of persecution, hallucinations, affective disturbances and perseverative behavior $^{6,9,40}$. AMPH psychosis usually dissipates upon the cessation of drug use, but there are also long-term sequelae associated with AMPH abuse. For example, re-exposure to a relatively low dose of AMPH will often precipitate a psychotic episode in former AMPH addicts who have been abstinent for months to years ${ }^{35,36,46}$. The enduring hypersensitivity to AMPH seen in former addicts suggests that chronic AMPH use has long-term effects on brain function.

A number of animal models have been developed to study the neurobiological consequences of chronic AMPH treatment. For example, AMPH addicts frequently take very high doses of AMPH in 'runs' that can last for 4-6 days ${ }^{21}$, and some researchers have attempted to capture this pattern of use by repeatedly administering very high doses of AMPH ( 10-20

Correspondence: T.E. Robinson, The University of Michigan, Neuroscience Laboratory Bldg., 1103 E. Huron St., Ann Arbor, MI 48109 , U.S.A. 
$\mathrm{mg} / \mathrm{kg}$ ) 2-6 times a day ${ }^{13,19,25,27,43,44,45}$. Others have continuously maintained elevated blood levels of AMPH with a slow-release subcutaneous implant ${ }^{12}$. These two approaches are usually neurotoxic, producing a permanent depletion of dopamine (DA) and serotonin $(5-\mathrm{HT})$ in selected brain regions ${ }^{11.30}$ (cf. ref. 48). A third approach has been to repeatedly and intermittently administer a constant low dose of AMPH $(\sim 1-5 \mathrm{mg} / \mathrm{kg})$ no more than twice a day. This latter treatment regimen is not neurotoxic, but produces a progressive and enduring enhancement (sensitization) in the motor stimulant effects of $\mathrm{AMPH}^{24}$. 30,42 and in AMPH-stimulated striatal DA release in vitro $^{20,29.31,49}$. It has been argued that the phenomenon of behavioral sensitization provides a good animal model of AMPH psychosis ${ }^{30.40}$.

Nevertheless, AMPH addicts initially take relatively low doses of AMPH, using higher doses only as they become tolerant to the euphorigenic and autonomic effects of $\mathrm{AMPH}^{7 \cdot 10.18 .21}$, and none of the approaches for studying chronic AMPH treatment mentioned above take this escalating pattern of AMPH use into account. It may be important to do so because the neurochemical effects of high doses of AMPH are changed by pretreatment with escalating doses of $\mathrm{AMPH}^{37.38}$. The present experiments were conducted, therefore, to determine the long-term effects of escalating (but non-toxic) doses of AMPH on: (1) regional brain concentrations of DA, 5-HT and their major metabolites; (2) spontaneous motor activity across the day-night cycle; and (3) in vivo extracellular concentrations of DA, dihydroxyphenylacetic acid (DOPAC), homovanillic acid (HVA) and 5-hydroxyindoleacetic acid (5-HIAA) in the ventral striatum (nucleus accumbens), both before and after a challenge injection of AMPH in freely moving rats. The ventral striatum was chosen for study because it has been implicated in the motor stimulant, affective, and rewarding effects of psychomotor stimulant drugs ${ }^{14.50}$.

\section{MATERIALS AND METHODS}

\section{Subjects and pretreatment regimen}

Adult female Holtzman rats (Holtzman, Madison, WI) were housed individually in a temperature-controlled room on a normal light:dark cycle $(14: 10 \mathrm{~h}$, with lights on at $08.00 \mathrm{~h}$ ), and with free access to food and water. Each rat received 2 daily intraperitoneal injections of either $0.9 \%$ saline or $(+)$-amphetamine sulfate (AMPH), with $8-10 \mathrm{~h}$ separating the two injections. After each injection the animals were placed back into their home cages and left undisturbed. Injections were given on consecutive weekdays, but not on weekends, and animals pretreated with AMPH received increasing doses of AMPH according to the schedule illustrated in Table I. Following the last injection of AMPH or saline the animals were left in their home cages until used in one of the two experiments described below.

Experiment 1. The effects of pretreatment with escalating doses of AMPH on spontaneous motor activity and postmortem tissue concentrations of monoamines and monoamine metabolites

Twenty-five days after the last pretreatment injection of AMPH or saline the animals were transferred from their home cage to automated activity monitors $(41 \times 24 \times 18 \mathrm{~cm})$, which are described in detail elsewhere ${ }^{33}$. The monitors detect movement from one end of the cage to the other (locomotion), and are not sensitive to small movements of the head or body made in one location. The animals remained in these monitors for $24 \mathrm{~h}$ /day for the next 5 days, and the number of photocell beam interruptions each animal made was cumulated over $30 \mathrm{~min}$ intervals for 20 $\mathrm{h} / \mathrm{day}$. The light-dark cycle was the same as in the main colony room. After this the animals were placed back into their home cages.

Three to four days later the animals were killed rapidly by decapitation. Each brain was removed

\section{TABLE I}

\section{Amphetamine pretreatment regimen}

The numbers represent $\mathrm{mg} / \mathrm{kg}$ of AMPH per injection (weight of the salt) on each pretreatment day. Animals received two injections/day (see Methods).

\begin{tabular}{llrrrrrr}
\hline Week & Day & \multicolumn{1}{c}{ W } & & & & & \\
& $M$ & $T$ & W & Th & $F$ & Sa & Su \\
\hline 1 & 1 & 1 & 2 & 2 & 2 & - & - \\
2 & 3 & 4 & 4 & 4 & 4 & - & - \\
3 & 4 & 5 & 5 & 5 & 5 & - & - \\
4 & 6 & 7 & 7 & 7 & 7 & - & - \\
5 & 8 & 9 & 9 & 9 & 9 & - & - \\
6 & 9 & 10 & 10 & 10 & 10 & - & - \\
\hline
\end{tabular}


from the cranium ( $30-45 \mathrm{~s}$ ), placed into ice-cold saline for approx. $30 \mathrm{~s}$, and then placed in a chilled cutting block. Coronal sections were obtained as described by Heffner et al. ${ }^{17}$ and the following regions dissected in ice-cold saline. (a) Frontal cortex. This consisted of the DA-rich anteromedial portion of the frontal cortex, from just anterior to the genu of the corpus callosum to the frontal pole. (b) Striatum. The corpus of the striatum was removed with a $3 \mathrm{~mm}$ diameter micropunch. (c) Nucleus accumbens. The nucleus accumbens was removed with a $2 \mathrm{~mm}$ diameter micropunch. (d) Hypothalamus. The entire hypothalamus was dissected as described by Heffner et al. ${ }^{17}$. Tissue from the left and right hemispheres was pooled, weighed, placed into tubes containing $0.05 \mathrm{~N}$ $\mathrm{HClO}_{4}$, with dihydroxybenzylamine added as an internal standard, and then homogenized. Samples were centrifuged at $5,000 \mathrm{~g}$ for $45 \mathrm{~min}$ at $2-4{ }^{\circ} \mathrm{C}$, the supernatant filtered through $0.45 \mu \mathrm{m}$ syringe filters (Gelman Sciences, LC3A) and stored frozen at $-20{ }^{\circ} \mathrm{C}$ until assayed for dopamine (DA), dihydroxyphenylacetic acid (DOPAC), homovanillic acid (HVA), 5-hydroxytryptamine (5-HT) and 5-hydroxyindoleacetic acid (5-HIAA) by HPLC-EC, as described previously ${ }^{32}$.

Experiment 2. The effects of pretreatment with escalating doses of $A M P H$ on behavior and the concentrations of DA, DOPAC, HVA and 5-HIAA in ventral striatal extracellular fluid in vivo, both before and after an $A M P H$ challenge

Fifteen to 21 days after the last pretreatment injection of AMPH or saline matched pairs of animals (one AMPH and one saline-pretreated) were anesthetized with sodium pentobarbital, supplemented with methoxyflurane, and placed into a stereotaxic instrument. Using standard stereotaxic techniques, a microdialysis probe was lowered into the ventral striatum in either the left or right hemisphere (half the animals received an implant on the left and half on the right). The term ventral striatum is used according to the terminology for brain DA systems suggested by Björklund and Lindvall ${ }^{1}$, and takes into account the concept of a ventral striatal region introduced by Heimer and Wilson ${ }^{16}$, consisting primarily of the nucleus accumbens and tuberculum olfactorium. During implantation a modified Ringer solution $\left(147 \mathrm{mM} \mathrm{Na}^{+}, 2.3 \mathrm{mM} \mathrm{Ca}^{2+}, 4 \mathrm{mM} \mathrm{K}^{+}\right.$and 155.6
$\mathrm{mM} \mathrm{Cl}-\mathrm{pH}$ 6.0) flowed continuously through the probe at approximately $1.0 \mu \mathrm{l} / \mathrm{min}$. The dialysis probe was fixed to the skull with stainless steel screws and dental acrylic, and the entire assembly was encased in a protective housing constructed from the dental acrylic. The inlet and outlet tubing was threaded through a coiled steel tether, and the inlet line connected to a single channel liquid swivel (Instech Laboratories, Plymouth Meeting, PA). The animals were then placed into a $29 \times 29 \times 31 \mathrm{~cm}$ high plexiglass test chamber and left there overnight, during which time Ringer solution was continuously pumped through the probes at $0.2 \mu \mathrm{l} / \mathrm{min}$ using a Harvard Model 22 syringe pump and $2.5 \mathrm{ml}$ gas-tight Hamilton 1000 series syringes.

The dialysis probes and method have been described in detail previously ${ }^{34}$. Briefly, the dialysis probe was of a concentric design and consisted of a $2.0 \mathrm{~mm}$ length of regenerated cellulose hollow dialysis fiber (Spectrum), which had an o.d. of $250 \mu \mathrm{m}$ and M.W. cut-off of 6000 . The outlet tube consisted of a $30 \mathrm{~cm}$ length of fused silica capillary tubing (Polymicro Technologies, Phoenix, AZ) with an o.d. of 150 $\mu \mathrm{m}$ and an i.d. of $75 \mu \mathrm{m}$. Dialysate was collected in minivials mounted on the tether approx. $25 \mathrm{~cm}$ above the animal and could be quickly exchanged without touching the animal. Prior to implantation all probes were tested for their ability to recover known concentrations of DA, DOPAC, HVA and 5-HIAA in vitro, at $37^{\circ} \mathrm{C}$ and a flow rate of $1.5 \mu \mathrm{l} / \mathrm{min}^{34}$.

Eighteen to $20 \mathrm{~h}$ after probe implantation the pump speed was set to $1.5 \mu \mathrm{l} / \mathrm{min}$, and after waiting at least $30 \mathrm{~min}$, dialysate samples were collected over $20 \mathrm{~min}$ intervals in tubes containing $10 \mu \mathrm{l}$ of $0.05 \mathrm{~N}$ $\mathrm{HClO}_{4}$, also containing $0.1 \mathrm{mM}$ sodium bisulfite and $0.2 \mathrm{mM}$ EDTA per $25 \mathrm{ml}$ of $\mathrm{HClO}_{4}$. At least 3 baseline samples were collected and then each animal received a challenge injection of $2.0 \mathrm{mg} / \mathrm{kg}$ of $(+)$ AMPH, and an additional 10 samples collected. This challenge dose was used because it was previously shown to be effective in behaviorally differentiating sensitized and control animals ${ }^{33}$. Dialysate was injected directly onto the HPLC column within $10 \mathrm{~min}$ after collection and without further treatment, using assay procedures described by Robinson and Whishaw $^{34}$.

The test chambers were located in a separate room, adjacent to the neurochemistry lab, and white 
noise was played continuously to mask sounds from nearby rooms. The animals were left undisturbed in this room, but were monitored from the neurochemistry lab by closed-circuit television. The experimenter entered the test room periodically only to quickly change sample collection vials.

The animals were video-taped during one $20 \mathrm{~min}$ baseline interval, and for $200 \mathrm{~min}$ following the AMPH challenge. Behavior was analyzed later by viewing the videotapes, often at $2-8 \times$ normal speed. Locomotor activity was estimated by counting the number of times an animal moved from one side of the cage to the other (crossovers), and the number of times an animal reared (both front feet off the ground), during consecutive $10 \mathrm{~min}$ intervals. Stereotyped behavior was quantified by an observer blind to pretreatment condition, who rated the occurrence of repetitive head and limb movements, and repetitive sniffing behavior, at the half-way point of each 20 min collection interval. Head and limb movements were rated as: $0=$ no head movements, or head movements associated with normal locomotion; $1=$ increased frequency of otherwise normal appearing head movements associated with hyperactivity; discontinuous; mild intensity; 2 = stereotyped (repetitive) up and down head movements and shuffling of the forepaws; discontinuous; $3=$ continuous, in place, repetitive head and limb movements; moderate intensity and frequency; $4=$ as 3 , but high intensity and frequency. Sniffing was rated as: $0=$ no sniffing, or a normal pattern of sniffing associated with breathing or normal exploration of an object or place; 1 = increased rate of sniffing associated with increased locomotion and rearing (hyperactivity); discontinuous; mild intensity; 2 = stereotyped sniffing (repetitive vibrissae and snout movements); discontinuous; not directed at a specific object or place; moderate intensity; 3 = continuous, in place repetitive vibrissae and snout movements; moderate intensity and frequency; $4=$ intense, continuous vibrissae and snout movements aimed at the cage floor.

At the completion of the dialysis experiment the animals were killed with an overdose of sodium pentobarbital and perfused through the heart, first with $0.9 \%$ saline, followed by $10 \%$ formalin in saline. The brains were removed and stored in $10 \%$ formalin. They were later frozen and horizontal sections prepared using standard histological techniques. The sections were stained with cresyl violet and examined to determine the location of the dialysis probe in each animal.

\section{RESULTS}

\section{Experiment 1}

Behavior. Fig. 1 shows the average locomotor activity counts for saline and AMPH-pretreated rats cumulated over $30 \mathrm{~min}$ intervals for $7.5 \mathrm{~h}$ prior to lights-off, the $10 \mathrm{~h}$ lights-off period, and then an additional $2.5 \mathrm{~h}$ after the lights came on. Data for the remaining $4 \mathrm{~h}$ were not included to minimize the disturbance associated with daily feeding, cage cleaning and data collection (printing). To reduce intrasubject variability in activity associated with the estrous cycle, the data were averaged over the 5 days of testing, during which time each animal would have had only one complete cycle.

Both groups showed a similar pattern of motor activity across most of the light-dark cycle. Activity levels were low during the afternoon, but rose slowly prior to lights off. There was a marked increase in locomotor activity when the lights initially went off. Activity subsided from this initial high to a low point $5 \mathrm{~h}$ after lights-off, but still remained higher than during the day. There was no difference between saline and AMPH-pretreated animals when all 40 intervals were analyzed, or when just daytime or nocturnal ac-

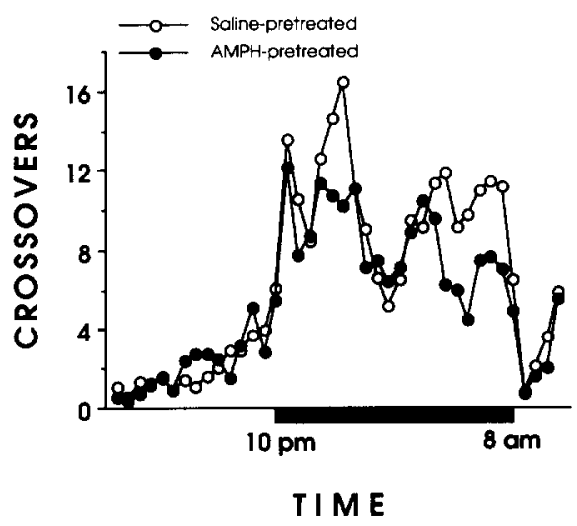

Fig. 1. The average frequency of photocell beam interruptions (crossovers) cumulated over $30 \mathrm{~min}$ intervals across the daynight cycle in amphetamine-pretreated (closed circles) and saline-pretreated (open circles) rats. The lights-off period, which started at $10.00 \mathrm{~h}$ and ended at $08.00 \mathrm{~h}$, is illustrated by the thick black line on the horizontal axis. 


\section{TABLE II}

Average ( \pm S.E.M.) regional concentrations ( $\mathrm{ng} / \mathrm{mg}$ wet tissue weight) of monoamines and monoamine metabolites in postmortem tissue obtained from amphetamine $(A M P H)$ - and saline-pretreated rats

\begin{tabular}{llcccc}
\hline Compound & Pretreatment & Striatum & Accumbens & Cortex & Hypothalamus \\
\hline DA & Saline & $14.23 \pm 0.43$ & $9.76 \pm 0.34$ & $0.022 \pm 0.007$ & $0.661 \pm 0.036$ \\
DOPAC & AMPH & $13.22 \pm 0.53$ & $9.41 \pm 0.33$ & $0.028 \pm 0.009$ & $0.678 \pm 0.028$ \\
& Saline & $1.11 \pm 0.06$ & $1.21 \pm 0.08$ & $0.057 \pm 0.007$ & $0.616 \pm 0.033$ \\
HVA & AMPH & $1.08 \pm 0.05$ & $1.28 \pm 0.05$ & $0.065 \pm 0.009$ & $0.679 \pm 0.042$ \\
& Saline & $0.978 \pm 0.065$ & $0.791 \pm 0.063$ & $0.073 \pm 0.010$ & - \\
5-HT & AMPH & $1.055 \pm 0.073$ & $0.854 \pm 0.042$ & $0.064 \pm 0.007$ & - \\
& Saline & $0.420 \pm 0.030$ & $0.893 \pm 0.103$ & $1.85 \pm 0.11$ & $1.83 \pm 0.09$ \\
5-HIAA & AMPH & $0.436 \pm 0.035$ & $1.041 \pm 0.133$ & $1.88 \pm 0.12$ & $1.82 \pm 0.10$ \\
& Saline & $0.614 \pm 0.019$ & $0.733 \pm 0.069$ & $0.729 \pm 0.052$ & $0.946 \pm 0.048$ \\
& AMPH & $0.616 \pm 0.014$ & $0.904 \pm 0.067$ & $0.771 \pm 0.050$ & $0.913 \pm 0.025$ \\
\hline
\end{tabular}

tivity was analyzed (2-way ANOVAs with repeated measures). AMPH-pretreated animals, however, tended to be less active than saline-pretreated controls towards the end of the dark period (2-way ANOVA on the last $2 \mathrm{~h}$ of nocturnal activity; $F_{1.18}=$ $4.24, P=0.054$, main effect). This was because saline-pretreated rats showed a statistically significant increase in activity from the low point during the middle of the night $(02.30-03.00 \mathrm{~h})$ to the last interval before lights on (1-way ANOVA for repeated measures, $\left.F_{10,90}=2.65, P=0.007\right)$, whereas AMPH-pretreated rats did not $\left(F_{10,90}=1.69, P=\right.$ 0.095; Fig. 1).

Neurochemistry. Table II shows the average postmortem tissue concentrations of DA, DOPAC, HVA, 5-HT and 5-HIAA in the striatum, nucleus accumbens, frontal cortex and hypothalamus, measured 33-34 days after the last pretreatment injection. There was no difference between the saline and AMPH-pretreated groups on any measure, in any structure ( $t$-tests). The DOPAC/DA, HVA/DA and 5-HIAA/5-HT ratios for each structure were also analyzed, and again there was no significant effect of AMPH pretreatment.

\section{Experiment 2}

Behavior. There was no difference in activity between saline- and AMPH-pretreated animals during baseline testing, and animals from both groups were very inactive as indicated by low levels of locomotion and rearing (Fig. 2). This was expected because testing took place during the lights-on period, and after the animals had been in the chambers for $18-20 \mathrm{~h}$.
The animals typically sat still, sometimes making small head movements, grooming or walking; but frequently they appeared to be asleep (curled immobile posture). They would often maintain this sleeping posture while sample collection tubes were exchanged.
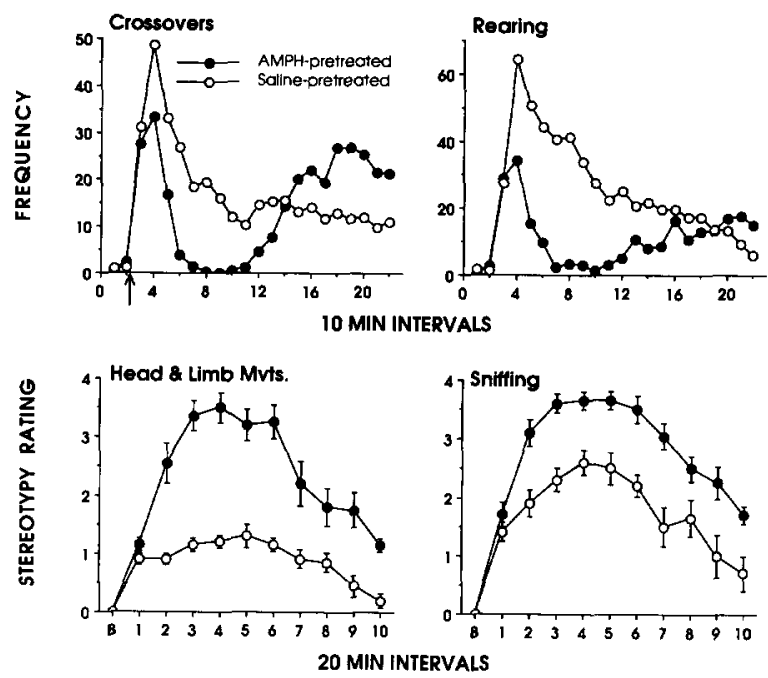

Fig. 2. The effects of pretreatment with saline (open symbols) or amphetamine (closed symbols) on behavior before and after a challenge injection of $2.0 \mathrm{mg} / \mathrm{kg}$ of amphetamine given $15-21$ days after the last pretreatment injection. The frequency of crossovers (locomotion from one side of the cage to the other) and rearing was cumulated over $10 \mathrm{~min}$ intervals, and the arrow in the upper left panel indicates when AMPH was given. Stereotypy ratings were obtained once during each 20 min interval (see Methods). B represents the average values obtained during baseline and the remaining symbols the average values obtained after the amphetamine challenge. For the stereotypy ratings \pm S.E.M. bars are also shown. Amphetamine-pretreated animals differed significantly from saline-pretreated animals on all measures (see text). 
In contrast, pretreatment condition had a large effect on the behavior produced by a challenge injection of $2.0 \mathrm{mg} / \mathrm{kg}$ of AMPH. In control animals AMPH caused marked hyperactivity, as indicated by high levels of locomotion and rearing (Fig. 2). The amount of locomotion and rearing increased quickly after the AMPH challenge, reaching a peak during the second $10 \mathrm{~min}$ interval after the injection. Although locomotion and rearing slowly declined over the remainder of the test session, motor activity remained higher than during baseline throughout the

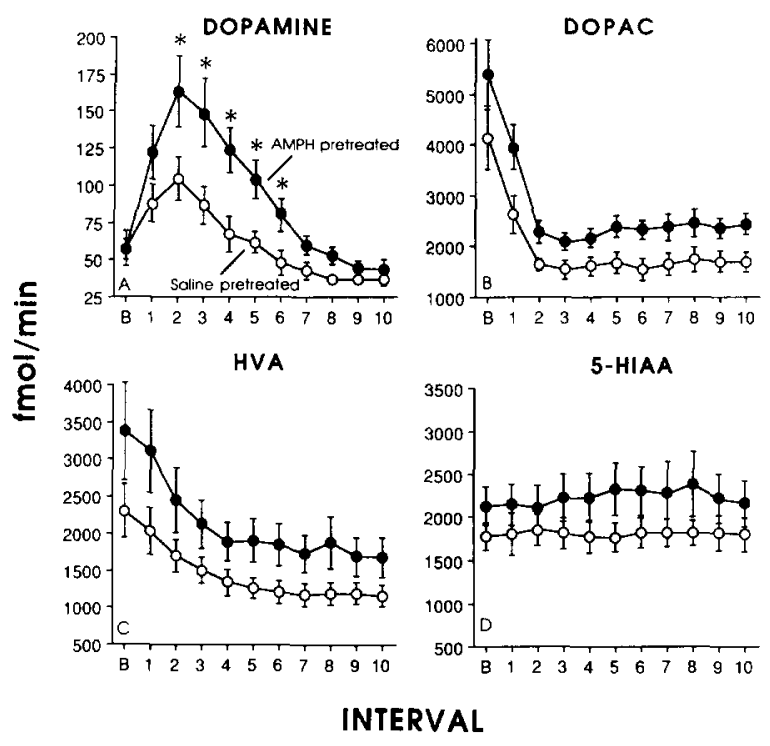

Fig. 3. The average ( \pm S.E.M.) extracellular fluid concentrations of dopamine $(A)$, DOPAC (B; dihydroxyphenylacetic acid), HVA (C; homovanillic acid) and 5-HIAA (D; 5-hydroxyindoleacetic acid) in ventral striatum in vivo, before $(B)$ and after (20 min intervals, $1-10)$ a challenge injection of 2.0 $\mathrm{mg} / \mathrm{kg}$ of amphetamine in rats that were pretreated with amphetamine (closed symbols) or saline (open symbols). All dialysis probes were tested for their ability to recover known concentrations of DA, DOPAC, HVA and 5-HIAA in vitro, and the values shown (in $\mathrm{fmol} / \mathrm{min}$ ) were corrected for recovery. The average relative recovery values were: DA $-18.8 \pm$ $0.7 \%$. DOPAC $-17.2 \pm 0.8 \%$; HVA $-16.8 \pm 1.1 \%$; and $5-$ HIAA $-16.3 \pm 0.9 \%$. The amphetamine challenge produced a significantly greater increase in extracellular DA in amphetamine-pretreated than in saline-pretreated rats. The results of a two-way analysis of variance for repeated measures on each compound were as follows: DA - effect of pretreatment, $F_{1,13}$ $=5.45 ; P=0.036$; effect of time, $F_{10.130}=30.3, P<0.001 ;$ pretreatment $\times$ time interaction, $F_{10131}=3.44 ; P<0.001 ;{ }^{*}, P<$ 0.05 , Scheffe tests. DOPAC - pretreatment, $F=6.43, P=$ 0.025 ; time, $F=33.6, P<0.001$; interaction, $F<1.0$, non-significant (n.s.). HVA - pretreatment, $F=2.91, P=0.11$; time, $F=21.5, P<0.001$; interaction, $F<1.0$, n.s. 5 -HIAA - pretreatment, $F=1.51, P=0.24$; time, $F<1.0$, n.s.; interaction, $F<1.0$. n.s. rest of the session. Hyperactivity was accompanied by an increase in sniffing behavior, but saline-pretreated animals did not develop focused stereotyped behavior - as indicated by maximal average stereotypy scores of only about 2.5 for sniffing and 1.0-1.5 for head and limb movements (Fig. 2). AMPH-pretreated rats, however, showed a behavioral syndrome typical of a higher dose of $\mathrm{AMPH}^{42}$. In this group the AMPH challenge produced an initial elevation in locomotion and rearing lasting for 20-30 $\mathrm{min}$, followed by a precipitous drop in locomotor activity to very low levels during the period lasting approximately 50-90 min after the injection (Fig. 2). During the period of reduced locomotor activity AMPH-pretreated rats showed intense focused stereotyped behavior - as indicated by average stereotypy ratings of approximately 3.5 (Fig. 2). This stereotypy phase was followed by a period of 'post-stereotypy hyperactivity ${ }^{.39}$, during which time the incidence of locomotion again increased (Fig. 2). Thus, animals pretreated with escalating doses of AMPH and given a challenge injection of $2.0 \mathrm{mg} / \mathrm{kg}$ of AMPH showed a multiphasic behavioral syndrome characteristic of highly sensitized animals ${ }^{39}$.

In vivo microdialysis. The changes in behavior produced by pretreatment with AMPH were accompanied by changes in the concentration of DA in extracellular fluid, but only following the AMPH challenge (Fig. 3A). During baseline there was no difference between saline- and AMPH-pretreated animals in the extracellular concentrations of DA in ventral striatum (in saline-pretreated rats it averaged $57.6 \pm$ 11.8 (S.E.M.) fmol $/ \mathrm{min}$ and in AMPH-pretreated rats $56.6 \pm 6.7 \mathrm{fmol} / \mathrm{min}$; values corrected for recovery; Fig. 3A). The challenge injection of AMPH produced a significant increase in the extracellular concentrations of DA in both saline- and AMPH-pretreated animals, and this peaked during the second $20 \mathrm{~min}$ interval in both groups. However, the AMPH-evoked rise in extracellular DA was significantly greater in AMPH-pretreated animals than in saline-pretreated animals (Fig. 3A). The two pretreatment groups did not differ significantly during the first 20 min interval following the AMPH challenge, but extracellular DA concentrations rose to a significantly higher peak in AMPH-pretreated animals and this difference persisted for the next $80 \mathrm{~min}$. By the end of the test session extracellular fluid con- 
centrations of DA had fallen to slightly below baseline levels in both groups, and at this time there was again no difference between the groups (Fig. 3A).

AMPH pretreatment also changed the extracellular concentrations of DOPAC and HVA (Fig. 3B,C). The extracellular concentration of DOPAC was significantly higher in AMPH-pretreated than in salinepretreated animals. A two-way ANOVA for repeated measures that included all 11 sample intervals resulted in a significant effect of pretreatment condition ( $P=0.025$; Fig. 3B), but no significant interaction $(F<1.0)$, suggesting the two groups differed at all points in time (including baseline). However, a $t$ test on just the baseline values did not reach statistical significance, probably because of greater variation in extracellular fluid DOPAC concentrations during baseline than following the AMPH challenge (see S.E.M. bars on Fig. 3B). There was also a significant effect of time $(P<0.001)$ because the AMPH challenge caused a large decline in extracellular DOPAC concentrations, which was maximal by the third 20 min interval after AMPH and persisted throughout the test session. The absence of a significant pretreatment $\times$ time interaction indicates that the rate of decline in DOPAC was the same for AMPH and saline-pretreated animals. AMPH pretreatment had a similar effect on extracellular HVA concentrations, in that the average concentrations were higher in AMPH-pretreated animals than in saline controls at all points in time; but this difference did not reach statistical significance $(P=0.11)$. The decline in HVA produced by the AMPH challenge was more gradual than for DOPAC (Fig. 3), but proceeded at the same rate in AMPH and saline-pretreated groups (the effect of time was significant, $P<$ 0.001 , but the interaction term was non-significant). Neither AMPH pretreatment $(P=0.24)$ nor the AMPH challenge $(F<1.0)$ had a significant effect on the concentration of 5-HIAA in ventral striatal extracellular fluid (Fig. 3D).

Histology. The location of each dialysis probe was estimated from examination of the histological sections. Neurochemical data from one rat were excluded because its probe was not in the ventral striatum. The remaining probes all extended ventrally into the olfactory tubercle; the deepest to $9.22 \mathrm{~mm}$ ventral from bregma (all coordinates refer to those on horizontal sections in Paxinos and Watson ${ }^{26}$ ). The first $250 \mu \mathrm{m}$

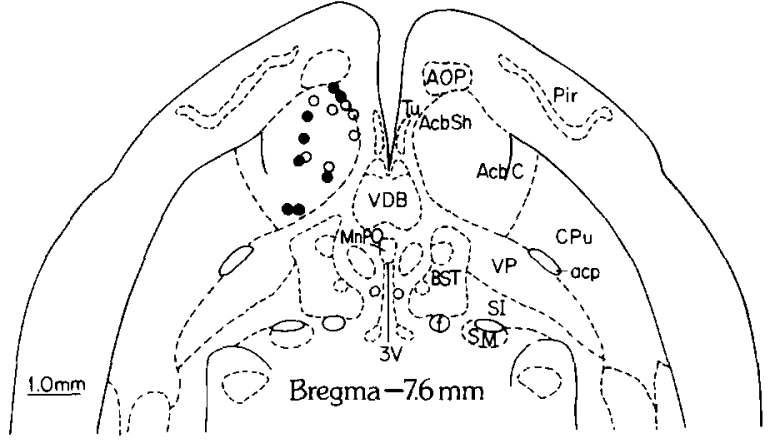

Fig. 4. Schematic drawing of the anterior portion of a horizontal section of rat brain adapted from Paxinos and Watson ${ }^{26}$ showing the area traversed by the dialysis probes. The horizontal plane represented by this plate (Fig. 95 in Paxinos and Watson ${ }^{26}$ ) is $7.6 \mathrm{~mm}$ ventral from bregma. Closed circles represent probes from amphetamine-pretreated animals and open circles probes from saline-pretreated animals. The diameter of each circle is drawn to scale, and thus illustrates the approximate diameter of a dialysis probe relative to the nucleus accumbens. Abbreviations: AcbC, nucleus accumbens, core; AcbSh, nucleus accumbens, shell; acp, anterior commissure, posterior; AOP, anterior olfactory nucleus, posterior; BST, bed nucleus of the stria terminalis; $\mathrm{CPu}$, caudate putamen; $\mathrm{f}$, fornix; MnPO, median preoptic nucleus; Pir, piriform cortex; SI, substantia innominata; SM, nucleus of the stria medullaris; Tu, olfactory tubercle; VDB, nucleus vertical limb diagonal band; $\mathrm{VP}$, ventral pallidum; $3 \mathrm{~V}$, third ventricle.

of each probe consisted of the epoxy plug, and the actual dialysis region extended for $2.0 \mathrm{~mm}$ dorsally from the top of the plug. In the majority of animals the region sampled extended from $8.35 \mathrm{~mm}$ to 6.35 $\mathrm{mm}$ ventral from bregma, in the dorsal-ventral plane. On average, approximately $12 \%$ of the dialysis surface was located in the olfactory tubercle and the cell bridges of the ventral striatum and $88 \%$ in the nucleus accumbens. Fig. 4 shows the location of the probes as they traversed the plane of a horizontal section located $7.60 \mathrm{~mm}$ ventral to bregma. In summary, the probes sampled the ventral striatum ${ }^{1.16}$ consisting primarily of the nucleus accumbens, and to a lesser extent the olfactory tubercle and cell bridges of the ventral striatum. The dialysis fibers did not extend dorsally into the caudate-putamen.

\section{DISCUSSION}

To summarize the major findings: (a) pretreatment with escalating doses of AMPH produced a large and persistent (15-20 days) hypersensitivity to the motor stimulant effects of an AMPH challenge; 
(b) behavioral sensitization was accompanied by an enhancement in ventral striatal DA neurotransmission in vivo; (c) AMPH pretreatment was not neurotoxic, in that regional brain concentrations of DA and 5-HT were normal in postmortem tissue; and (d) AMPH pretreatment did not produce persistent (25-30 days) alterations in spontaneous motor activity across the day-night cycle. The implications of these findings are discussed below.

\section{Behavior}

Spontaneous motor activity over the light-dark cycle was relatively normal in AMPH-pretreated rats by $25-30$ days after the cessation of drug treatment. The only difference between saline and AMPH-pretreated animals was that the former group showed an increase in activity towards the end of the dark period and the latter group did not. This resulted in slightly lower activity scores in AMPH-pretreated rats during the last couple of hours before lights-on. In contrast, Robinson and Camp ${ }^{33}$ reported that the same escalating dose regimen as used here produced a significant decrease in nocturnal activity. But Robinson and Camp ${ }^{33}$ measured activity $8-12$ days following the cessation of drug treatment, and in the present study animals were withdrawn for 25-30 days. A comparison of the two studies suggests that the hypoactivity seen following withdrawal from this escalating dose regimen ${ }^{33}$ largely dissipates in about one month.

Despite relatively normal levels of spontaneous motor activity there was a large effect of AMPH pretreatment on the behavioral response to a challenge injection of AMPH. In control animals the AMPH challenge produced general hyperactivity. In AMPH-pretreated animals it produced intense focused stereotyped behavior, and a multiphasic pattern of locomotion. Thus, in AMPH pretreated rats the AMPH challenge produced a behavioral syndrome characteristic of a hyperdopaminergic state $^{39.41}$, indicating that even after 21 days of withdrawal AMPH-pretreated animals were still highly sensitized. The behavioral response to a challenge with $2.0 \mathrm{mg} / \mathrm{kg}$ of AMPH seen here was very similar to that reported previously in animals withdrawn from escalating dose AMPH treatment for only 12 days $^{33}$. This suggests that the hypersensitivity to the motor stimulant effects of AMPH persists unabated for at least 21 days after the last pretreatment injection, and perhaps for much longer ${ }^{30}$.

The behavioral hypersensitivity to an AMPH challenge reported here was qualitatively similar to the effects of a more typical constant low dose regimen, as were the neurochemical sequelae $e^{4,5,30,39,41,42}$. In contrast, the effects were quite different from those produced by neurotoxic treatment regimens (ref. 30 for review). The escalating dose regimen mimics to some extent the pattern of drug use seen in addicts, and therefore, the data further support the idea that the sensitization phenomenon provides a good animal model for studying the neurobiology of AMPH psychosis ${ }^{30.40}$ - whether sensitization is induced by pretreatment with constant low doses or escalating doses of AMPH.

Nevertheless, there are differences between constant low dose and escalating dose regimens. We cannot directly compare the magnitude of the behavioral syndrome reported here with the syndrome produced by a lower constant dose regimen, because of methodological differences in how behavior was quantified. But differences in the amount of individual variation suggest that treatment with escalating doses produces much more intense sensitization. In the present study every animal pretreated with AMPH showed vigorous stereotyped behavior, as indicated by the cessation of locomotor activity between about 50 and $90 \mathrm{~min}$ after the challenge injection of 2.0 $\mathrm{mg} / \mathrm{kg}$ (Fig. 5). In comparison, when Camp and Rob-

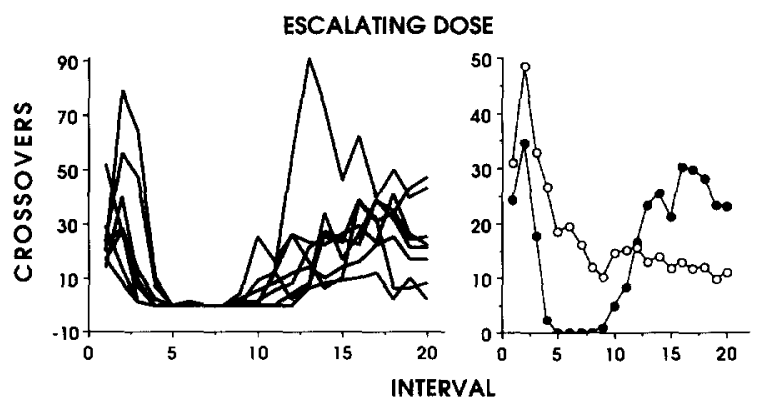

Fig. 5. Left: the frequency of crossovers in the 8 individual female rats pretreated with escalating doses of amphetamine during the twenty $10 \mathrm{~min}$ intervals following a challenge injection of $2.0 \mathrm{mg} / \mathrm{kg}$ of amphetamine. Each line represents data from one rat. Right: the average frequency of crossovers for the same 8 rats (closed symbols) and for saline-pretreated rats (replotted from Fig. 2 for ease of comparison). Note that all amphetamine-pretreated rats showed a triphasic response pattern. 
inson ${ }^{5}$ pretreated rats with one injection of $2.6 \mathrm{mg} / \mathrm{kg}$ of AMPH every 3 days, for a total of 9 injections, and also challenged them with $2.0 \mathrm{mg} / \mathrm{kg}$, there was a great deal of individual variation in response to the challenge (Fig. 6). In the latter instance some animals showed stereotyped behavior and a multiphasic pattern of locomotion, but others showed only hyperactivity. Marked individual variation in sensitization is typical of the constant low dose regimen, as discussed recently by Segal and Kuczenski ${ }^{41}$ and Camp and Robinson ${ }^{4.5}$ (see ref. 28 for review).

The relative absence of individual variation in behavioral response to a challenge seen with the escalating dose regimen may present some advantages in studying sensitization, especially in trying to identify reliable neural correlates of sensitization. The escalating dose regimen may also be advantageous for studying the complex pattern of changes that occur over time following withdrawal from repeated AMPH use. For example, the hypoactivity seen early after withdrawal from an escalating dose regimen ${ }^{33}$ may be homologous to the dysphoric 'crash' described in AMPH addicts following withdrawal ${ }^{7.21}$. On the other hand, the escalating dose regimen may obscure important individual differences in the susceptibility to sensitization ${ }^{28}$. A constant low dose regimen may be more suitable for studying factors that

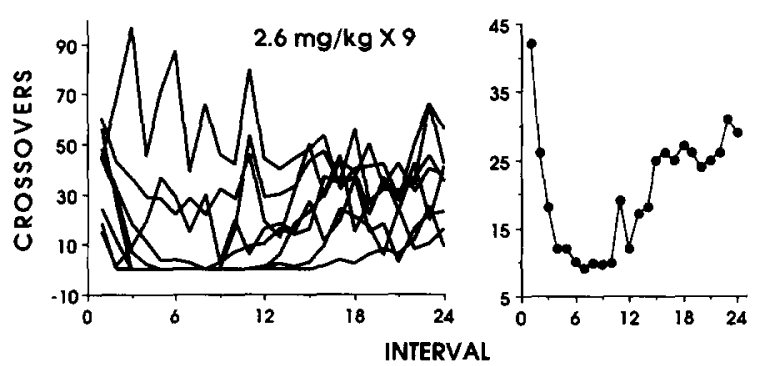

Fig. 6. Left: the frequency of crossovers in 8 individual female rats that were pretreated with one injection of $2.6 \mathrm{mg} / \mathrm{kg}$ of amphetamine every 3 days, for a total of 9 injections, and then 3 days after the last pretreatment injection were given a challenge injection of $2.0 \mathrm{mg} / \mathrm{kg}$ (data from ref. 5). Data are shown for twenty-four 5 min intervals after the amphetamine challenge, and each line represents data from 1 animal. The eight animals were selected from a larger group of 15 animals to illustrate the range of individual variation in response to the challenge. Right: the average frequency of crossovers in the total group of 15 animals given this pretreatment regimen (replotted from Fig. $3 \mathrm{~F}$ in Camp and Robinson ${ }^{5}$ ). The individual variation illustrated here is typical of the sensitization produced by a constant low dose regimen (also see refs. 28, 41). Compare this with the level of individual variation illustrated in Fig. 5. render some individuals very susceptible to sensitization and others relatively resistant.

\section{Neurochemistry}

In Experiment 1 animals were killed 33-34 days after the last injection of AMPH and postmortem tissue concentrations of monoamines were measured. There was no effect of AMPH pretreatment on DA, DOPAC, HVA, 5-HT or 5-HIAA levels, or on metabolite/transmitter ratios, in the striatum, nucleus accumbens, frontal cortex or hypothalamus. This finding is important because it establishes that the escalating dose regimen used here is not neurotoxic, in agreement with Robinson and Camp ${ }^{33}$. However, we reported previously that basal DA metabolism is elevated in sensitized animals after shorter periods of withdrawal (9-12 days) ${ }^{5.33}$, and in this experiment, in which animals were withdrawn for 33 days, no such changes were evident. A major difference between our earlier studies ${ }^{5.33}$ and the present study is the length of the withdrawal period, which suggests that sensitization-related changes in basal DA metabolism do not persist over a month following withdrawal. This is not to say that DA systems are normal after a month of withdrawal, because AMPH-stimulated striatal DA release in vitro is still enhanced ${ }^{20,31}$. Perhaps measures of basal DA activity, and especially measures of DA metabolism, are relatively insensitive indicators of sensitization-related changes in neural activity. After a long period of withdrawal sensitization-related changes in neural activity may be apparent only following a challenge stimulus, such as reexposure to $\mathrm{AMPH}^{30}$ or exposure to stress ${ }^{32}$. This is consistent with the behavioral phenomenon, because after a month of withdrawal sensitized animals appeared quite normal behaviorally - until challenged (see above). Alternatively, the effects on DA metabolism reported previously could represent an exaggerated response to the stress associated with the decapitation procedure ${ }^{33}$.

The most important finding in the present study is that behavioral sensitization was accompanied by an enhancement in DA neurotransmission in vivo. This is the first report on the long-term consequences of repeated AMPH use in which behavioral measures and measures of DA neurotransmission in the ventral striatum were obtained simultaneously from the same animals, both before and after an AMPH chal- 
lenge. There was no difference between AMPH- and saline-pretreated rats in the extracellular concentration of DA during the resting state, just as there was no difference in behavior during the resting state. A challenge injection of AMPH elevated the extracellular concentration of DA in both groups, but to a significantly greater extent in AMPH-pretreated rats than in saline-pretreated controls. That is, the hyperdopaminergic behavioral syndrome seen in sensitized animals following an AMPH challenge occurred in association with a significantly elevated extracellular concentration of DA in the ventral striatum.

The sensitization-related elevation in the extracellular concentration of DA seen following the AMPH challenge could be due to an increase in DA release, a decrease in DA reuptake, a decrease in DA metabolism or a decrease in AMPH metabolism ${ }^{22}$. Decreased AMPH metabolism could result in higher brain levels of AMPH in sensitized animals (and thus greater DA release), but the available evidence does not support this hypothesis ${ }^{8.30}$. In fact, brain levels of AMPH are reduced in rats given escalating doses of meth-AMPH ${ }^{38}$. We can also eliminate decreased DA metabolism, because the extracellular concentrations of DA metabolites tended to be elevated in sensitized animals (also see refs. 5, 33). It is more difficult to dissociate a change in reuptake from a change in release. There was no effect of AMPH pretreatment on the rate of decline of either DOPAC or HVA following the AMPH challenge. If the decline in DOPAC and HVA is due to AMPH's ability to block DA reuptake ${ }^{22}$, resulting in less DA available for intraneuronal metabolism, these results would suggest there was no sensitization-related change in reuptake. However, the decline in DOPAC produced by AMPH may not be due to AMPH's effect on reuptake, but to an AMPH-induced depletion of newlysynthesized cytosolic $\mathrm{DA}^{2.51}$, thus removing, 'the main intraneuronal substrate for MAO and thereby reducing DA metabolite levels ${ }^{, 52}$ (p.8). Therefore, the present data do not allow us to choose with confidence between release and reuptake hypotheses. Nevertheless, we favor the idea that the elevated extracellular concentrations of DA seen in sensitized animals are due to an increase in the ability of AMPH to induce DA release, because: (a) a sensitization-related enhancement in DA release has been reported in in vitro superfusion studies, in which the effects of reuptake are minimized ${ }^{29,31.49}$; and (b) one would expect that a change in the reuptake carrier would result in higher extracellular concentrations of DA during the resting state, and there were none.

The data suggest that an enduring enhancement in DA neurotransmission, characterized by an increase in the releasability of DA, may be responsible for the enduring changes in behavior produced by past experience with $\mathrm{AMPH}$. It is worth noting in this regard that activation of DA systems appears to be necessary for the development of behavioral sensitization, because concomitant treatment with a DA antagonist prevents sensitization to $\mathrm{AMPH}^{23,47}$. The data presented here, however, do not allow us to ascertain the direction of putative cause-effect relations - i.e. does the increase in DA release cause the enhanced behavioral response, or vice versa? It is important to also consider, therefore, that a similar elevation in AMPH-stimulated DA release has been described in related studies involving the superfusion of dorsal striatal tissue in vitro ${ }^{29,31,49}$. The in vitro experiments show that behavioral activation is not necessary to demonstrate a sensitization-related enhancement in DA release, thus supporting the idea that an elevation in DA release is responsible for the development of behavioral sensitization.

The mechanism responsible for the enhancement in DA release is unknown, but the effect does not appear to be specific to AMPH-stimulated DA release. Castañeda et al. ${ }^{3}$ recently reported that AMPH pretreatment also enhances striatal DA release evoked by high $\mathrm{KCl}$ or electrical field stimulation in vitro ${ }^{3}$. It has been hypothesized that a change in the intracellular distribution of DA could account for both an increase in AMPH-evoked and depolarization-evoked DA release ${ }^{3}$, but whether such a mechanism is involved in the phenomenon reported here remains to be determined. Whatever the mechanism, it is capable of producing very long-lasting changes in behavior as a result of past experience, and therefore, may represent a type of neuronal plasticity common to other forms of behavioral adaptation (e.g. ref. 15).

\section{ACKNOWLEDGEMENTS}

Support from the Scottish Rite Schizophrenia Research Program and the National Institutes of Health 
(NS00844 and DA04294) is gratefully acknowledged. Development of the dialysis method was supported in part by a grant from the Rackham School of

\section{REFERENCES}

1 Björklund, A. and Lindvall, O., Dopamine containing systems in the CNS. In A. Björklund and T. Hökfelt (Eds.), Handbook of Chemical Neuroanatomy, Vol. 2: Classical Transmitters in the CNS, Part 1, Elsevier, Amsterdam, 1984, pp. 55-122.

2 Butcher, S.P., Fairbrother, I.S., Kelly, J.S. and Arbuthnott, G.W., Amphetamine-induced dopamine release in the rat striatum: an in vivo microdialysis study, J. Neurochem., 50 (1988) 346-355.

3 Castañeda, E., Becker, J. and Robinson, T.E., The longterm effects of repeated amphetamine treatment in vivo on amphetamine, $\mathrm{KCl}$ and electrical stimulation evoked striatal dopamine release in vitro, Life Sci., 42 (1988) 2447-2456.

4 Camp, D.M. and Robinson, T.E., Susceptibility to sensitization. I. Sex differences in the enduring effects of chronic D-amphetamine treatment on locomotion, stereotyped behavior and brain monoamines, Behav. Brain Res., in press.

5 Camp, D.M. and Robinson, T.E., Susceptibility to sensitization. II. The influence of gonadal hormones on enduring changes in brain monoamines and behavior produced by the repeated administration of $\mathrm{D}$-amphetamine or restraint stress, Behav. Brain Res., in press.

6 Connell, P.H., Amphetamine Psychosis, Chapman and Hill, London, 1958.

7 Davis, J.M. and Schlemmer, R.F., The amphetamine psychosis. In J. Caldwell (Ed.), Amphetamines and Related Stimulants, CRC Press, Boca Raton, FL, 1980, pp. 161-173.

8 Demellweek, C. and Goudie, A.J., Behavioural tolerance to amphetamine and other psychostimulants: the case for considering behavioral mechanisms, Psychopharmacology, 80 (1983) 287-307.

9 Ellinwood, E.H., Amphetamine psychosis: I. Description of the individuals and processes, J. Nerv. Ment. Dis., 144 (1967) 273-283.

10 Ellinwood, E.H., Amphetamine psychosis: individuals, settings, and sequences. In E.H. Ellinwood and S. Cohen (Eds.), Current Concepts on Amphetamine Abuse, U.S. Government Printing Office, Washington, DC, 1972, pp. 143-157.

11 Ellison, G.D. and Eison, M.S., Continuous amphetamine intoxication: an animal model of the acute psychotic episode, Psychol. Med., 13 (1983) 751-762.

12 Ellison, G.D., Eison, M.S., Huberman, H.S. and Daniel, F., Long-term changes in dopaminergic innervation of caudate nucleus after continuous amphetamine administration, Science, 201 (1978) 276-278.

13 Fibiger, H.C. and McGeer, E.G., Effects of acute and chronic methamphetamine treatment on tyrosine hydroxylase activity in brain and adrenal medulla, Eur. J. Pharmacol., 16 (1971) 176-180.

14 Fibiger, H.C. and Phillips, A., Reward, motivation, cognition: psychobiology of mesotelencephalic dopamine systems. In Handbook of Physiology, Vol. IV, Intrinsic Regulatory Systems of the Brain, American Physiological Society, Bethesda, MD, 1986, pp. 647-675.
Graduate Studies .(University of Michigan). We thank Dr. J.B. Becker for her helpful comments and assistance.

15 Hawkins, R.D. and Kandel, E.R., Is there a cell-biological alphabet for simple forms of learning?, Psychol. Rev., 91 (1984) 375-391.

16 Heimer, L. and Wilson, R.D., The subcortical projections of the allocortex: similarities in the neural associations of the hippocampus, the piriform cortex, and the neocortex. In M. Santini (Ed.), Golgi Centennial Symposium Proceedings, Raven, New York, 1975, pp. 177-193.

17 Heffner, T.G., Hartman, J.A. and Seiden, L.S., A rapid method for the regional dissection of the rat brain, Pharmacol. Biochem. Behav., 13 (1980) 453-456.

18 Jönsson, L.E., Pharmacological blockade of amphetamine effects in amphetamine dependent subjects, Eur. J. Clin. Pharmacol, 4 (1972) 206-211.

19 Koda, L.Y. and Gibb, J.W., Adrenal and striatal tyrosine hydroxylase activity after methamphetamine, J. Pharmacol. Exp. Ther., 185 (1973) 42-48.

20 Kolta, M.G., Shreve, P., De Souza, V. and Uretsky, N.J., Time course of the development of the enhanced behavioral and biochemical responses to amphetamine after pre. treatment with amphetamine, Neuropharmacology, 24 (1985) 823-829.

21 Kramer, J.C., Fischman, V.S. and Littlefield, D.C., Amphetamine abuse, JAMA, 201 (1967) 89-93.

22 Kuczenski, R., Biochemical actions of amphetamine and other stimulants. In I. Creese (Ed.), Stimulants: Neurochemical Behavioral and Clinical Perspectives, Raven, New York, 1983, pp. 31-61.

23 Kuczenski, R. and Leith, N.J., Chronic amphetamine: is dopamine a link in or mediator of the development of tolerance and reverse tolerance?, Pharmacol. Biochem. Behav., 15 (1981) 405-413.

24 Magos, L., Persistence of the effect of amphetamine on stereotyped activity in rats, Eur. J. Pharmacol., 6 (1969) 200-201.

25 Morgan, M.E. and Gibb, J.W., Short-term and long-term effects of methamphetamine on biogenic amine metabolism in extra-striatal dopaminergic nuclei, Neuropharmacology, 19 (1980) 989-995.

26 Paxinos, G. and Watson, C., The Rat Brain in Stereotaxic Coordinates, 2nd edn., Academic Press, New York, 1986.

27 Ridley, R.M., Baker, H.F., Owen, F., Cross, A.J. and Crow, T.J., Behavioural and biochemical effects of chronic amphetamine treatment in the vervet monkey, Psychopharmacology, 78 (1982) 245-251.

28 Robinson, T.E., Stimulant drugs and stress: factors influencing individual differences in the susceptibility to sensitization. In C. Barnes and P. Kalivas (Eds.), Sensitization of the Nervous System, Telford Press, Caldwell, NJ, in press.

29 Robinson, T.E. and Becker, J.B., Behavioral sensitization is accompanied by an enhancement in amphetamine-stimulated dopamine release from striatal tissue in vitro, Eur. $J$. Pharmacol., 85 (1982) 253-254.

30 Robinson, T.E. and Becker, J.B., Enduring changes in brain and behavior produced by chronic amphetamine administration: a review and evaluation of animal models of amphetamine psychosis, Brain Res. Rev., 11 (1986) 
157-198.

31 Robinson, T.E., Becker, J.B. and Presty, S.K.. Long-term facilitation of amphetamine-induced rotational behavior and striatal dopamine release produced by a single exposure to amphetamine: sex differences, Brain Research, 253 (1982) 231-241

32 Robinson. T.E., Becker, J.B., Young, E.A., Akil, H. and Castañeda, E., The effects of footshock stress on regional brain dopamine metabolism and pituitary $\beta$-endorphin release in rats previously sensitized to amphetamine, Neuropharmacology, 26 (1987) 679-691.

33 Robinson, T.E. and Camp, D.M., Long-lasting effects of escalating doses of D-amphetamine on brain monoamines. amphetamine-induced stereotyped behavior and spontaneous nocturnal locomotion, Pharmacol. Biochem. Behav. 26 (1987) 821-827.

34 Robinson, T.E. and Whishaw, I.Q., Normalization of extracellular dopamine in striatum following recovery from a partial unilateral 6-OHDA lesion of the substantia nigra: a microdialysis study in freely moving rats, Brain Research, 450 (1988) 209-224.

35 Sato. M., Acute exacerbation of methamphetamine psychosis and lasting dopaminergic supersensitivity - a clinical survey, Psychopharmacol. Bull., 22 (1986) 751-756.

36 Sato, M., Chen. C.-C., Akiyama, K. and Otsuki, S., Acute exacerbation of paranoid psychotic state after long-term abstinence in patients with previous methamphetamine psychosis, Biol. Psychiat., 18 (1983) 429-440.

37 Schmidt. C.J.. Sonsalla, P.K., Hanson, G.R., Peat, M.A. and Gibb, J.W., Methamphetamine-induced depression of monoamine synthesis in the rat: development of tolerance. J. Neurochem., 44 (1985) 852-855.

38 Schmidt, C.J., Gehlert, D.R., Peat, M.A., Sonsalla, P.K. Hanson, G.R., Wamsley, J.K. and Gibb, J.W., Studies on the mechanism of tolerance to methamphetamine, Brain Research, 343 (1985) 305-313.

39 Segal, D.S. Behavioral and neurochemical correlates of repeated D-amphetamine administration, $A d v$. Biochem. Psychopharmacol., 13 (1975) 247-262.

40 Segal, D.S., Geyer, M.A. and Schuckit, M.A., Stimulantinduced psychosis: an evaluation of animal models. In M.B.H. Youdim, W. Lovenberg, D.F. Sharman and J.R. Lagnado (Eds.), Essays in Neurochemistry and Neuropharmacology, Vol. 5, Wiley, London, 1981, pp. 95-129.

41 Segal, D.S. and Kuczenski, R., Individual differences in responsiveness to single and repeated amphetamine adminis- tration: behavioral characteristics and neurochemical correlates, J. Pharmacol. Exp. Ther., 242 (1987) 917-926.

42 Segal, D.S. and Mandell, A.J., Long-term administration of amphetamine: progressive augmentation of motor activity and stereotypy, Pharmacol. Biochem. Behav., 2 (1974) 249-255.

43 Seiden, L.S., Fischman, M.W. and Schuster, C. R., Longterm methamphetamine induced changes in brain catecholamines in tolerant rhesus monkeys, Drug Alcohol Depend., $1(1975 / 76) 215-219$.

44 Trulson, M.E. and Crisp, T., Behavioral effects of serotonergic and dopaminergic drugs in cats following chronic amphetamine administration, Eur. J. Pharmacol., 99 (1984) 313-324.

45 Trulson, M.E. and Jacobs, B.L., Long-term amphetamine treatment decreases brain serotonin metabolism: implications for theories of schizophrenia, Science, 205 (1979) $1295-1297$

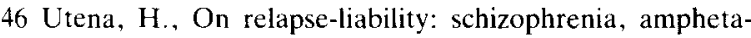
mine psychosis and animal model. In H. Mitsuda and T. Fukuda (Eds.), Biological Mechanisms of Schizophrenia and Schizophrenia-Like Psychoses, Igaku Shoin, Tokyo, 1974, p. 285.

47 Vezina, P. and Stewart, J., The effects of D-1 and D-2 dopamine receptor antagonists on the development of sensitization to the locomotor effects of morphine and amphetamine. Soc. Neurosci. Abstr., 13 (1987) 450.

48 Vogel, H.W., Miller, J., Waxman, H. and Gottheil, E., Biochemical and behavioral changes in rats during and af ter chronic D-amphetamine exposure, Drug Alcohol Depend., 15 (1985) 245-253.

49 Wilcox, R.A., Robinson, T.E. and Becker, J.B., Enduring enhancement in amphetamine-stimulated striatal dopamine release in vitro produced by prior exposure to amphetamine or stress in vivo, Eur. J. Pharmacol., 124 (1986) 375-376.

50 Wise, R.A. and Bozarth, M.A., A psychomotor stimulant theory of addiction, Psychol. Rev., 94 (1987) 469-492.

51 Zetterström, T., Sharp, T. and Ungerstedt, U., Effect of neuroleptic drugs on striatal dopamine release and metabolism in the awake rat studied by intracerebral dialysis, Eur. J. Pharmacol., 106 (1984) 27-37.

52 Zetterström, T., Sharp. T. and Ungerstedt, U., Further evaluation of the mechanism by which amphetamine reduces striatal dopamine metabolism: a brain dialysis study, Eur. J. Pharmacol., 132 (1986) 1-9. 